\title{
Baicalin attenuates oxygen-glucose deprivation- induced injury by inhibiting oxidative stress-mediated 5-lipoxygenase activation in PC12 cells
}

\author{
Cheng-tan $\mathrm{LI}^{1,2}$, Wei-ping ZHANG ${ }^{1}$, San-hua FANG ${ }^{1}$, Yun-bi $\mathrm{LU}^{1}$, Li-hui ZHANG ${ }^{2}$, Ling-ling $\mathrm{QI}^{1}$, Xue-qin HUANG ${ }^{1}$, Xiao-jia \\ HUANG $^{1}$, Er-qing WEI ${ }^{1, *}$
}

${ }^{1}$ Department of Pharmacology, School of Medicine, Zhejiang University, Hangzhou 310058, China; ${ }^{2}$ Hangzhou Key Laboratory of Neurobiology and Department of Pharmacology, School of Basic Medicine, Hangzhou Normal University, Hangzhou 310036, China

\begin{abstract}
Aim: To determine whether the flavonoid baicalin attenuates oxygen-glucose deprivation (OGD)-induced injury by inhibiting oxidative stress-mediated 5-lipoxygenase (5-LOX) activation in PC12 cells.

Methods: The effects of baicalin and the 5-LOX inhibitor zileuton on the changes induced by OGD/recovery or $\mathrm{H}_{2} \mathrm{O}_{2}$ (an exogenous reactive oxygen species [ROS]) in green fluorescent protein-5-LOX-transfected PC12 cells were compared.

Results: Both baicalin and zileuton attenuated OGD/recovery- and $\mathrm{H}_{2} \mathrm{O}_{2}$-induced injury and inhibited OGD/recovery-induced production of 5-LOX metabolites (cysteinyl leukotrienes) in a concentration-dependent manner. However, baicalin did not reduce baseline cysteinyl leukotriene levels. Baicalin also reduced OGD/recovery-induced ROS production and inhibited 5-LOX translocation to the nuclear envelope and p38 phosphorylation induced by $\mathrm{OGD} /$ recovery and $\mathrm{H}_{2} \mathrm{O}_{2}$. In contrast, zileuton did not show these effects.

Conclusion: Baicalin can inhibit 5-LOX activation after ischemic injury, which may partly result from inhibition of the ROS/p38 mitogenactivated protein kinase pathway.
\end{abstract}

Keywords: baicalin; 5-lipoxygenase; rat pheochromocytoma (PC12) cell; oxygen-glucose deprivation; reactive oxygen species; p38 mitogen-activated protein kinase

Acta Pharmacologica Sinica (2010) 31: 137-144; doi: 10.1038/aps.2009.196

\section{Introduction}

5-Lipoxygenase (5-LOX, EC 1.13.11.34) is a key enzyme in catalyzing the conversion of arachidonic acid to its metabolites, including leukotriene $\mathrm{B}_{4}\left(\mathrm{LTB}_{4}\right)$, cysteinyl leukotrienes (CysLTs, namely $\mathrm{LTC}_{4}, \mathrm{LTD}_{4}$, and $\mathrm{LTE}_{4}$ ) and 5S-hydroxy-6,8,11,14eicosatetraenoic acid (5-HETE $)^{[1,2]}$. 5-LOX is distributed in the cytosol, nucleus, or both in resting cells depending on the cell type ${ }^{[2,3]}$. When cells are stimulated, 5-LOX is translocated from the intracellular pool to the nuclear envelope where it interacts with its co-factors, 5-LOX activating protein (FLAP) and phospholipase $\mathrm{A}_{2}$, to form an active complex for metabolite production ${ }^{[3]}$. Therefore, as one of the characteristics of 5-LOX activation, its translocation to the nuclear envelope is critical for its enzymatic activation and is a target for antiinflammatory 5-LOX inhibitors ${ }^{[3]}$.

5-LOX metabolites play an important role in inflammatory

\footnotetext{
* To whom correspondence should be addressed.

E-mail weieq2006@zju.edu.cn

Received 2009-10-22 Accepted 2009-12-03
}

diseases of the peripheral tissues and the central nervous system, such as bronchial asthma ${ }^{[4,5]}$ and ischemic brain injury ${ }^{[6-9]}$. In these diseases, various stimuli activate 5-LOX through two main ways. Specifically, elevation of intracellular calcium that generally occurs after excitotoxicity and mitogen-activated protein kinase (MAPK)-regulated phosphorylation that can be induced by oxidative stress ${ }^{[3]}$ both activate 5-LOX. Previously, we reported that 5-LOX can be activated after ischemic brain injury in rats ${ }^{[8,10]}$, after oxygen-glucose deprivation (OGD)induced ischemic injury in cultured neurons and in pheochromocytoma (PC12) cells ${ }^{[11-14]}$. In primary neuron cultures, OGD induces release of excitatory amino acids that activate NMDA receptors to elevate intracellular calcium, resulting in 5-LOX translocation to the nuclear envelope and activation of 5-LOX to produce CysLTs ${ }^{[12]}$. Calcium-dependent 5-LOX activation is also found in PC12 cells after exposure to NMDA ${ }^{[15]}$. In addition, we recently found oxidative stress-induced 5-LOX activation in ischemic PC12 cells. OGD increases the release of reactive oxygen species (ROS), which activate 5-LOX through the p38 MAPK pathway ${ }^{[14]}$. Therefore, ischemic 5-LOX activation 
can be regulated by both elevated intracellular calcium after excitotoxicity and the activated MAPK pathway after oxidative stress.

Baicalin is one of the predominant flavonoids isolated from the dry roots of Scutellaria baicalensis Georgi (Huang Qin) with multiple pharmacological effects in peripheral organs and tissues ${ }^{[16-19]}$. Baicalin also exerts a protective effect on ischemic brain injury ${ }^{[20-23]}$. Previously, we reported that baicalin attenuates in vitro ischemic-like injury in rat primary cortical neurons $^{[13]}$ and hippocampal slices ${ }^{[24]}$, and this effect partly relates to the inhibition of NMDA receptor-mediated 5-LOX activation in the neurons ${ }^{[13]}$.

Thus, baicalin can inhibit ischemic 5-LOX activation induced by excitotoxicity; however, whether it also inhibits oxidative stress-induced 5-LOX activation is unknown. Therefore, to determine whether baicalin can inhibit oxidative stressinduced 5-LOX activation, we investigated the effect of baicalin on the changes induced by OGD and hydrogen peroxide $\left(\mathrm{H}_{2} \mathrm{O}_{2}\right.$, an exogenous ROS) in green fluorescent protein (GFP)5-LOX-transfected PC12 cells. To clarify the properties of 5-LOX inhibition, we compared the effects of baicalin and the 5-LOX inhibitor zileuton, an iron-ligand inhibitor, on these cells following $\mathrm{OGD}^{[25,26]}$.

\section{Materials and methods Materials}

Dulbecco's modified Eagle's medium (DMEM) and horse serum were purchased from Gibco (Carlsbad USA). Fetal bovine serum (FBS) was obtained from Sijiqing Biol Inc. (Hangzhou, China). The polyclonal antibody against 5-LOX and CysLT enzyme immunoassay (EIA) kit were purchased from Cayman Chemicals (Ann Arbor, MI, USA). The monoclonal antibody against phosphorylated p38 and the polyclonal antibody against p38 were obtained from Santa Cruz Biotechnology Inc (Santa Cruz, USA). 3-(4,5-dimethyml2-thiazolyl)-2,5-diphenyl-2H-tetraxolium bromide (MTT), 2,7-dichlorofluorescin diacetate (DCF-DA), baicalin, and $\mathrm{H}_{2} \mathrm{O}_{2}$ were purchased from Sigma-Aldrich (St Louis, USA) and zileuton from Gaomeng Pharmaceutical Co (Beijing, China).

\section{Cell culture and 5-LOX transfection}

PC12 cells were purchased from the Institute of Cell Biology at the Chinese Academy of Sciences (Shanghai, China) and maintained at $37^{\circ} \mathrm{C}$ in a humidified incubator containing $5 \% \mathrm{CO}_{2}$ in high-glucose DMEM supplemented with $10 \%$ heat-inactivated horse serum, 5\% FBS, $100 \mathrm{U} / \mathrm{mL}$ penicillin and $100 \mu \mathrm{g} / \mathrm{mL}$ streptomycin.

The pEGFP-C2/5-LOX (GFP-5-LOX) and pEGFP-C2 null vectors (gifts from Professor Funk CD, University of Pennsylvania, USA [now in Queen's University, Canada]) were transfected into PC12 cells as we recently reported ${ }^{[14]}$. PC12 cell lines stably expressing GFP or GFP-5-LOX have been characterized by fluorescence microscopy and Western blot analy$\mathrm{sis}^{[14]}$. To detect GFP-5-LOX translocation, the transfected cells cultured on glass slips were washed with phosphate buffered saline (PBS) and immediately fixed with $4 \%$ paraformalde- hyde. Then the cells were observed under a fluorescence microscope (Olympus BX51, Tokyo, Japan).

\section{OGD, $\mathrm{H}_{2} \mathrm{O}_{2}$ and agent treatments}

PC12 cells were exposed to OGD as described previous$1 y^{[11,12,14]}$. Briefly, cells were rinsed twice and incubated in glucose-free Earle's solution. The cells were then introduced into an anaerobic chamber containing a mixture of $95 \% \mathrm{~N}_{2}$ and $5 \% \mathrm{CO}_{2}$ at $37^{\circ} \mathrm{C}$ for $2 \mathrm{~h}$. This procedure decreased $\mathrm{pO}_{2}$ in the solutions from $154.0 \pm 7.3$ to $23.9 \pm 5.1 \mathrm{mmHg}$ (mean $\pm \mathrm{SD}, n=5$ ). At the end of 2-h OGD, the media were replaced and cells were cultured in normal condition for $0.5 \mathrm{~h}$ (for ROS measurement), $1.5 \mathrm{~h}$ (for p38 determination), $2 \mathrm{~h}$ (for 5-LOX translocation), $3 \mathrm{~h}$ (for measurement of CysLTs) or $24 \mathrm{~h}$ (for cell viability) of recovery, as previously reported ${ }^{[14]} \cdot \mathrm{H}_{2} \mathrm{O}_{2}$ was freshly prepared from an $8.8 \mathrm{~mol} / \mathrm{L}$ stock solution before use, and PC12 cells were treated with $\mathrm{H}_{2} \mathrm{O}_{2} 160 \mu \mathrm{mol} / \mathrm{L}$ for $20 \mathrm{~min}$ (for p38 determination), $40 \mathrm{~min}$ (for 5-LOX translocation) or $24 \mathrm{~h}$ (for cell viability) at $37^{\circ} \mathrm{C}$, as previously reported ${ }^{[14]}$. Baicalin and zileuton at designated concentrations were continuously applied from 30 min before exposure to OGD or $\mathrm{H}_{2} \mathrm{O}_{2}$ until the end of recovery or $\mathrm{H}_{2} \mathrm{O}_{2}$ treatment.

\section{Cell viability and death assay}

Cell viability was determined by MTT assay. Briefly, at the end of the experiments, the cells cultured on 96-well plates were incubated with $0.5 \mathrm{mg} / \mathrm{mL}$ MTT for $2 \mathrm{~h}$ at $37^{\circ} \mathrm{C}$. Then the supernatant was carefully removed, $100 \mu \mathrm{L}$ of dimethyl sulfoxide was added into each well, and the absorbance of $490 \mathrm{~nm}$ of the MTT product formazan was determined on a Microplate Recorder (ELX 800, Bio-TEK instruments Inc, USA). The results are expressed as the percentage of control. Because the main type of OGD/recovery-induced cell death is necrosis ${ }^{[14]}$, we detected necrotic cells by propidium iodide (PI) staining. Cells were planted on glass coverslips. After treatment, cells were stained with $10 \mathrm{mg} / \mathrm{mL}$ of PI (Sigma-Aldrich) for $10 \mathrm{~min}$ at $37^{\circ} \mathrm{C}$. Then the cells were photographed under a fluorescence microscope (Olympus BX51) at excitation and emission wavelengths of $536 \mathrm{~nm}$ and $620 \mathrm{~nm}$, respectively. The necrotic cells with red nuclei stained by PI were counted by a researcher who was blind to the treatments, and reported as percentages of total cells.

\section{Western blotting analysis}

Cells were collected and washed twice with ice-cold PBS, pH 7.4, then lysed for $30 \mathrm{~min}$ on ice in lysis buffer $(100 \mathrm{mmol} / \mathrm{L}$ $\mathrm{NaCl}, 1 \%$ Nonidet P-40, 0.1\% SDS, 1\% deoxycholic acid, 10\% glycerol, $1 \mathrm{mmol} / \mathrm{L}$ EDTA, $1 \mathrm{mmol} / \mathrm{L}$ sodium orthovanadate, $50 \mathrm{mmol} / \mathrm{L}$ sodium fluoride, $1 \mathrm{mmol} / \mathrm{L}$ phenylmethylsulfonyl fluoride, $10 \mu \mathrm{g} / \mathrm{mL}$ leupeptin, and $1 \mu \mathrm{g} / \mathrm{mL}$ aprotinin). Cell lysates were obtained by centrifugation at $12000 \times g$ for 15 min at $4{ }^{\circ} \mathrm{C}$. Protein samples $(60 \mu \mathrm{g})$ were separated by $10 \%$ sodium dodecyl sulfate (SDS)-polyacrylamide gel electrophoresis and transferred to nitrocellulose membranes. The membranes then were blocked by $10 \%$ fat-free milk and incubated with a mouse monoclonal antibody against phosphorylated 
p38 (1:300) or a rabbit polyclonal antibody against p38 (1:300). Then they were incubated with horseradish peroxidase (HRP)conjugated goat anti-rabbit IgG (0.16 mg/L, Sigma-Aldrich) or HRP-conjugated goat anti-mouse IgM (1:3000, Zhongshan Biotechnology, Beijing, China) after repeated washing. Finally, the membranes were incubated with enzymatic chemiluminescence reagents and exposed on an X-ray film. The protein bands on the X-ray film were quantitatively analyzed with a laser densitometer (Ultro Scan XL, Pharmacia LKB Co, Stockholm, Sweden).

\section{Measurement of CysLTs}

Samples $(100 \mu \mathrm{L})$ were removed from culture media after 2 -h OGD and 0.5-h recovery and prepared according to previously reported method ${ }^{[12,14]}$. Produced CysLTs (including LTC $_{4}$, $\mathrm{LTD}_{4}$, and $\mathrm{LTE}_{4}$ ) were measured by EIA kits according to the manufacturer's instructions and calculated as $\mathrm{pg} / \mathrm{mg}$ protein.

\section{Measurement of intracellular ROS}

Following 2-h OGD and 0.5-h recovery, cells cultured on 96-well plate were rinsed with Earle's solution and incubated with $25 \mu \mathrm{mol} / \mathrm{L}$ DCF-DA in Earle's solution with glucose for $30 \mathrm{~min}$ at $37^{\circ} \mathrm{C}$. Then the cells were rinsed twice to remove excess probe, and fluorescence was measured with a multiwell plate fluorescence reader (FluoStar, Offenburg, Germany). The results are expressed as the percentage of control.

\section{Statistical analysis}

Data are reported as mean \pm SD. Statistical comparisons were made by one-way ANOVA followed by Tukey's multiple comparisons tests or unpaired Student's $t$-tests to detect significant difference using SPSS 10.0 for Windows. $P<0.05$ was considered to be statistically significant.

\section{Results}

\section{OGD/recovery-induced injury}

Cell injury was aggravated in GFP-5-LOX-transfected PC12 cells after 2-h OGD and 24-h recovery. Baicalin (1-10 $\mu \mathrm{mol} / \mathrm{L})$ and zileuton $(1-100 \mu \mathrm{mol} / \mathrm{L})$ attenuated the reduction in cell viability after OGD/recovery in both GFP- and GFP-5LOX-transfected PC12 cells (Figure 1A and 1B). In addition, baicalin $(0.1 \mu \mathrm{mol} / \mathrm{L})$ increased the cell viability in GFP-5LOX-transfected PC12 cells (Figure 1A). As analyzed by PI staining (Figure 1C), baicalin $(0.1-10 \mu \mathrm{mol} / \mathrm{L})$ and zileuton (0.1-10 $\mu \mathrm{mol} / \mathrm{L})$ reduced OGD/recovery-induced necrosis in a concentration-dependent manner (Figure 1D and 1E). Baicalin $(0.01 \mu \mathrm{mol} / \mathrm{L})$ also reduced the necrosis in GFP-5-LOXtransfected PC12 cells (Figure 1D). These results confirm that OGD/recovery injury was more severe in GFP-5-LOX-transfected PC12 cells than in GFP-transfected cells and indicate that both agents exerted protective effects on OGD/recoveryinduced cell injury.

\section{OGD/recovery-induced 5-LOX translocation}

The transfected GFP-5-LOX was localized in cell nuclei, as determined by fluorescence microscopy. Specifically, GFP-5-
LOX was translocated into the nuclear envelope after 2-h OGD and 2 -h recovery (Figure $2 \mathrm{~A})$. Baicalin $(0.1-10 \mu \mathrm{mol} / \mathrm{L}) \mathrm{sig}$ nificantly inhibited GFP-5-LOX translocation in a concentration-dependent manner, but zileuton did not have this effect (Figure 2B and 2C).

\section{OGD/recovery-induced production of CysLTs}

After 2-h OGD and 3-h recovery (a peak time point for CysLT production), CysLT levels increased from 139.8 \pm 13.9 to $261.1 \pm 33.7 \mathrm{pg} / \mathrm{mg}$ proteins in the culture media. Baicalin and zileuton $(10 \mu \mathrm{mol} / \mathrm{L})$ significantly reduced OGD/recoveryinduced production of CysLTs. However, baicalin, but not zileuton, did not reduce the baseline level of CysLTs (Figure 3). We did not measure CysLT levels after exposure to $\mathrm{H}_{2} \mathrm{O}_{2}$ because the measurement failed in our recent study ${ }^{[14]}$.

\section{OGD/recovery-induced ROS production and $\mathrm{H}_{2} \mathrm{O}_{2}$-induced injury}

We measured intracellular levels of ROS by 2,7-dichlorofluorescin diacetate (DCF-DA) assay in the wild-type PC12 cells but not in the GFP- or GFP-5-LOX-transfected cells because the GFP fluorescence interferes with the fluorescence generated in the assay. After 2-h OGD and 0.5-h recovery (a time point when ROS production reached the maximum), ROS increased from $100 \% \pm 11 \%$ to $412 \% \pm 93 \%$. Baicalin $(0.1-10 \mu \mathrm{mol} / \mathrm{L})$ reduced ROS production in a concentration-dependent manner, but zileuton did not affect ROS production (Figure $4 \mathrm{~A}$ and 4B).

To further determine the effects of baicalin and zileuton on oxidative stress-induced injury, we used the exogenous ROS $\mathrm{H}_{2} \mathrm{O}_{2}$ to induce oxidative injury in PC12 cells. $\mathrm{H}_{2} \mathrm{O}_{2}(160$ $\mu \mathrm{mol} / \mathrm{L})$ reduced cell viability more profoundly in GFP-5LOX-transfected cells than in GFP-transfected cells. However, baicalin and zileuton (1-10 $\mu \mathrm{mol} / \mathrm{L})$ significantly decreased the reduction in viability (Figure $4 \mathrm{C}$ and $4 \mathrm{D})$. Baicalin $(0.1$ $\mu \mathrm{mol} / \mathrm{L})$ also reduced $\mathrm{H}_{2} \mathrm{O}_{2}$-induced cell injury in GFP-5-LOXtransfected PC12 cells (Figure 4C).

\section{$\mathrm{H}_{2} \mathrm{O}_{2}$-induced 5-LOX translocation}

Similar to OGD injury, $\mathrm{H}_{2} \mathrm{O}_{2}(160 \mu \mathrm{mol} / \mathrm{L}$ for $40 \mathrm{~min})$ induced GFP-5-LOX translocation to the nuclear envelope by $54.7 \% \pm 7.3 \%$. Furthermore, baicalin $(1-10 \mu \mathrm{mol} / \mathrm{L})$ inhibited GFP-5-LOX translocation in a concentration-dependent manner, but zileuton did not (Figure 5).

\section{Phosphorylation of p38}

Phosphorylation of p38 is induced by OGD/recovery (the maximum phosphorylation was induced by 2-h OGD and 1.5-h recovery) or $\mathrm{H}_{2} \mathrm{O}_{2}$ (the maximum by $160 \mu \mathrm{mol} / \mathrm{L}$ for 20 $\min )^{[14]}$. Thus, we observed the effects of the agents on p38 phosphorylation after OGD/recovery and exposure to $\mathrm{H}_{2} \mathrm{O}_{2}$ in such conditions. We found that baicalin $(1-10 \mu \mathrm{mol} / \mathrm{L})$, but not zileuton (1-10 $\mu \mathrm{mol} / \mathrm{L})$, significantly inhibited p38 phosphorylation induced by OGD/recovery and $\mathrm{H}_{2} \mathrm{O}_{2}$ (Figure 6).

\section{Discussion}

In the present study, we found that baicalin attenuated isch- 

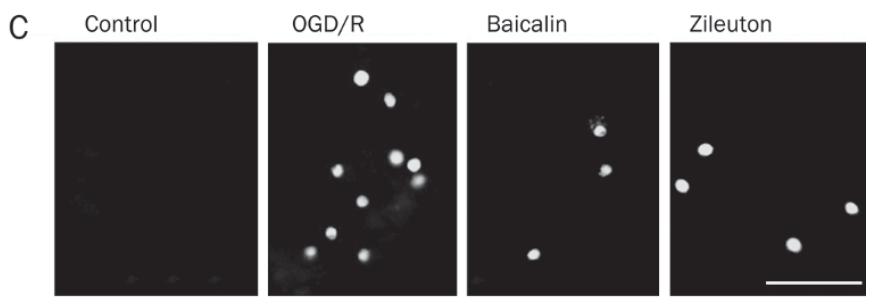

PC12/GFP-5-LOX
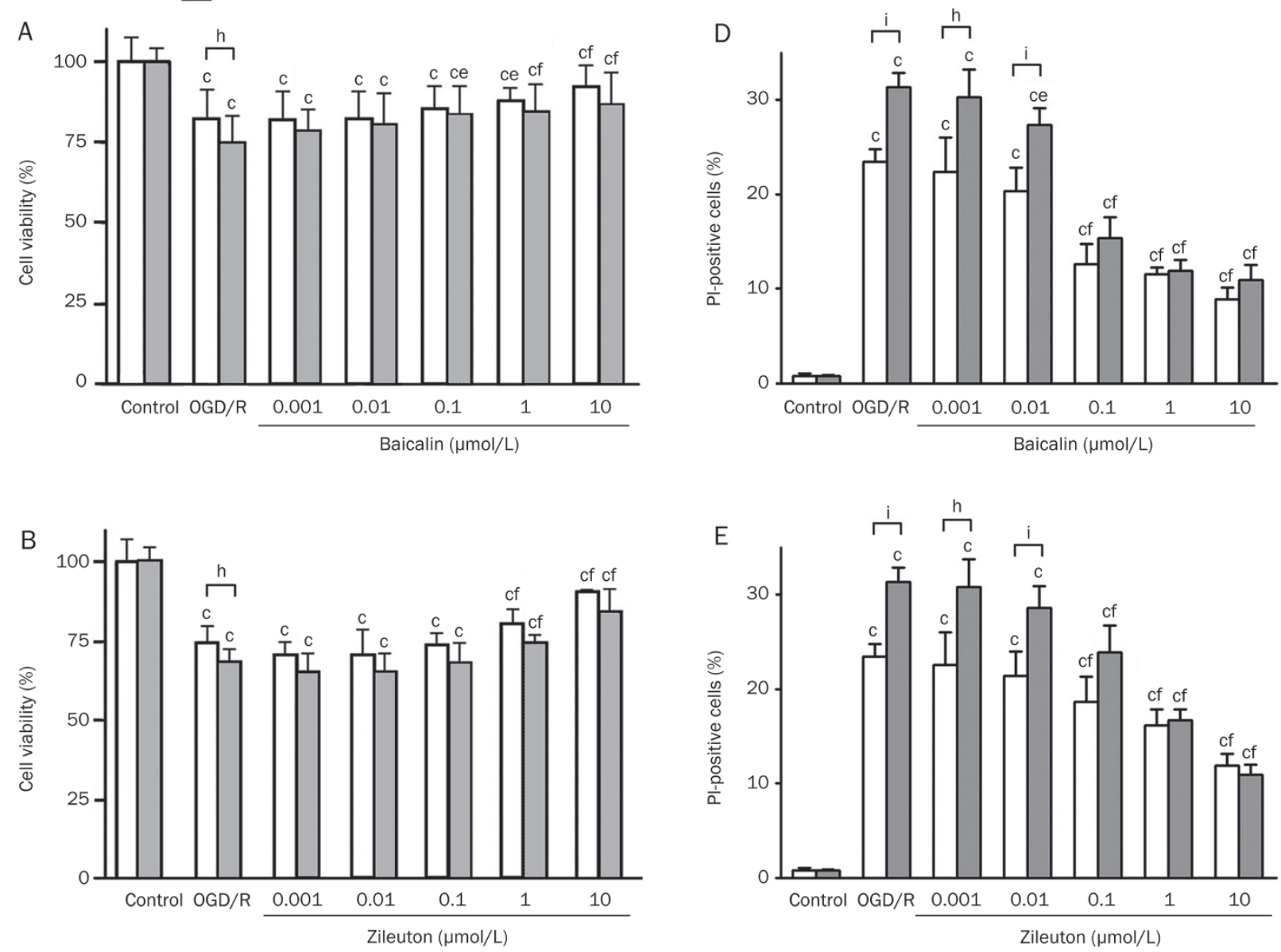

Figure 1. Effects of baicalin and zileuton on cell injury induced by OGD/recovery in PC12 cells. Cell viability was reduced after 2-h OGD and 24-h recovery in both GFP- and GFP-5-LOX-transfected cells. (A and B) Viability was significantly lower in GFP-5-LOX-transfected cells than in GFP-transfected cells. Baicalin and zileuton attenuated $\mathrm{OGD} /$ recovery-induced injury in both type cells in a concentration-dependent manner. (C) Cell death (necrosis) was evaluated by PI fluorescence staining in GFP-5-LOX-transfected PC12 cells (Scale bar=40 $\mu \mathrm{m}$ ). (D and E) Baicalin and zileuton inhibited OGD/ recovery-induced cell death in a concentration-dependent manner. Data are reported as mean \pm SD. $n=15-17(A$ and $B)$ or $4(D$ and $E)$. ${ }^{b} P<0.05$, ${ }^{\mathrm{c}} P<0.01$ vs corresponding control; ${ }^{\mathrm{e}} P<0.05,{ }^{\mathrm{f}} P<0.01$ vs $0 \mathrm{GD} /$ recovery alone; ${ }^{\mathrm{h}} \mathrm{P}<0.05,{ }^{\mathrm{i}} \mathrm{P}<0.01$ vs GFP-transfected cells.

emic injury in PC12 cells, and this effect was partly mediated by oxidative stress-induced 5-LOX activation through the p38 MAPK pathway. These results support our recent findings that baicalin protects against OGD injury ${ }^{[13]}$. This protective action is mediated via inhibition of 5-LOX activity. As evidence supporting the involvement of 5-LOX in injury, both baicalin and the 5-LOX inhibitor zileuton inhibited the production of CysLTs and attenuated cell injury after exposure to OGD and $\mathrm{H}_{2} \mathrm{O}_{2}$. However, baicalin showed a different action from zileuton on 5-LOX activation. Specifically, baicalin inhibited 5-LOX translocation and activation by reducing ROS production after exposure to OGD and p38 phosphorylation after exposure to OGD and $\mathrm{H}_{2} \mathrm{O}_{2}$ whereas zileuton directly inhibited 5-LOX enzymatic activity.

In the present study, we used PC12 cells transfected with GFP-5-LOX to visualize 5-LOX translocation and to enhance 5-LOX expression. The transfected GFP-5-LOX was primarily localized in nuclei $i^{[14,27]}$. We previously demonstrated involvement of the ROS/p38 MAPK pathway of 5-LOX activation after ischemic-like injury as well as the two modes of action of 5-LOX inhibitors (anti-oxidative or direct inhibitors) in GFP-5-LOX-transfected PC12 cells ${ }^{[14]}$. Here we found that 

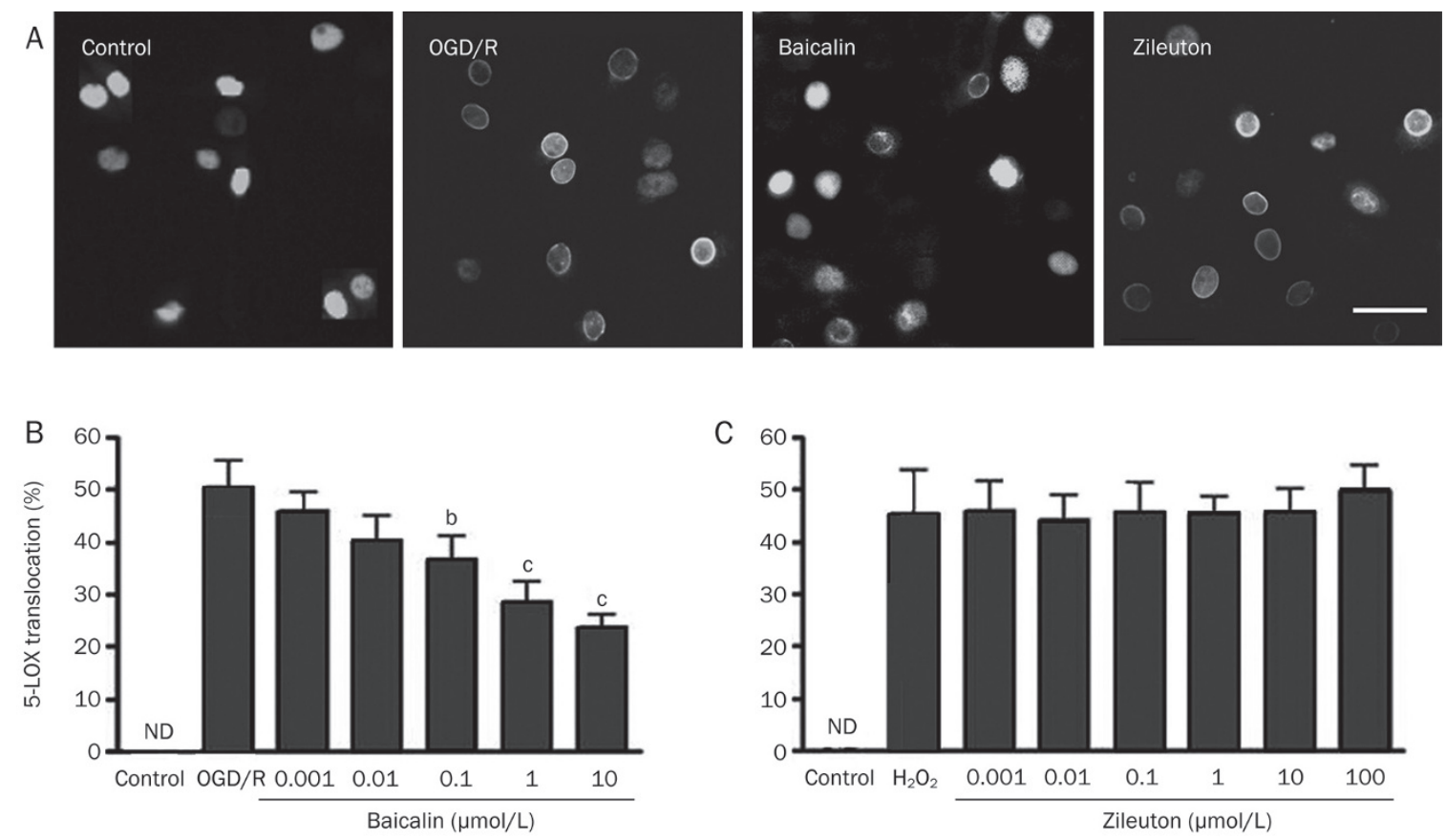

Figure 2. Effects of baicalin and zileuton on 5-LOX translocation after OGD/recovery in GFP-5-LOX-transfected PC12 cells. (A) GFP-5-LOX was translocated into the nuclear envelope after 2-h OGD and 2-h recovery, which was inhibited by baicalin (1 $\mu$ mol/L) but not by zileuton (1 $\mu$ mol/L). Scale bar $=40 \mu \mathrm{m}$. (B and C) Concentration-dependent results are summarized as mean \pm SD. $n=6 .{ }^{b} P<0.05,{ }^{c} P<0.01$ vs $0 G D /$ recovery alone. ND, not detectable.

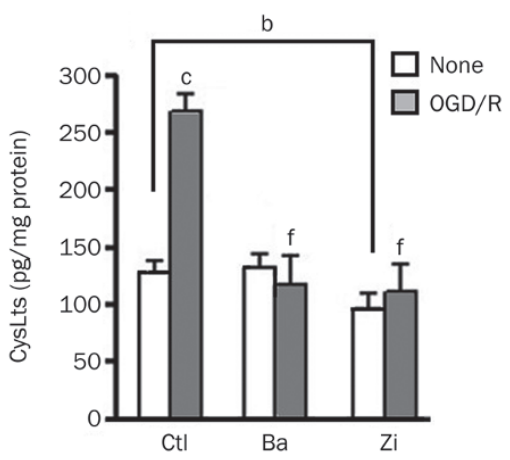

Figure 3. Effects of baicalin and zileuton on production of CysLTs after OGD/recovery in GFP-5-LOX-transfected PC12 cells. Baicalin (Ba, 10 $\mu \mathrm{mol} / \mathrm{L}$ ) reduced only the increased production whereas zileuton $(\mathrm{Zi}, 10$ $\mu \mathrm{mol} / \mathrm{L}$ ) reduced both baseline and the increased production of CysLTs after $\mathrm{OGD} /$ recovery. Data are reported as mean \pm SD. $n=4 .{ }^{\mathrm{b}} P<0.05$, ${ }^{\mathrm{c}} P<0.01$ vs control (no treatment). ${ }^{\mathrm{f}} P<0.01$ vs $\mathrm{OGD} /$ recovery alone.

baicalin acts as an anti-oxidative inhibitor for 5-LOX. Unlike the typical 5-LOX inhibitor zileuton, baicalin did not inhibit baseline 5-LOX enzymatic activity but did inhibit the activity after OGD/recovery. Consistently, it has been reported that baicalin shows no inhibition of isolated potato 5-LOX ${ }^{[28]}$ and non-stimulated rat cortical neurons ${ }^{[13]}$. Moreover, baicalin showed anti-oxidative activity because it reduced ROS production. These results indicate that baicalin might inhibit oxidative stress-induced 5-LOX activation rather than directly inhibit 5-LOX. Therefore, in addition to inhibiting 5-LOX activation induced by the elevated intracellular $\mathrm{Ca}^{2+}$ via NMDA receptor activation ${ }^{[13]}$, baicalin also inhibits 5-LOX activation via the ROS/p38 MAPK pathway. In addition, there is crosstalk between NMDA-induced excitotoxicity and oxidative stress $^{[29,30]}$, and baicalin inhibits 5-LOX activation after NMDA receptor-mediated excitotoxicity ${ }^{[13]}$. Whether baicalin affects a common pathway of 5-LOX activation in both pathological processes requires further investigation.

The signaling family of MAPKs includes extracellular signal-regulated kinases (ERKs), c-Jun $\mathrm{N}$-terminal kinases/ stress-activated protein kinases (JNK/SAPKs), and p38 enzymes $^{[31-33]}$. As one type of cell stress, ROS activates the p38 MAPK signal pathway, but not the ERK and JNK pathways, after OGD-induced ischemic injury in PC12 cells ${ }^{[14]}$. In a human B-lymphocyte cell line and in human polymorphonuclear leukocytes, p38 MAPK is activated independently of $\mathrm{Ca}^{2+}$ by chemical stress (sodium arsenite), osmotic stress (sorbitol, $\mathrm{NaCl})$, heat shock or oxidative stress $\left(\mathrm{H}_{2} \mathrm{O}_{2}\right.$, diamide), which leads to 5-LOX phosphorylation and activation ${ }^{[34,35]}$. Recently, we found that the p38 inhibitor SB203580 inhibited 5-LOX activation induced by $\mathrm{OGD} /$ recovery and $\mathrm{H}_{2} \mathrm{O}_{2}{ }^{[14]}$. In the present study, baicalin inhibited p38 phosphorylation induced by both OGD/recovery and $\mathrm{H}_{2} \mathrm{O}_{2}$, supporting the conclusion that it inhibits 5-LOX activation through the ROS/p38 MAPK pathway. Our findings also confirm the role of p38 MAPK in cell stress-induced 5-LOX activation ${ }^{[3]}$.

In the present study, we compared the effects of baicalin and zileuton. Zileuton is a specific 5-LOX inhibitor that chelates 

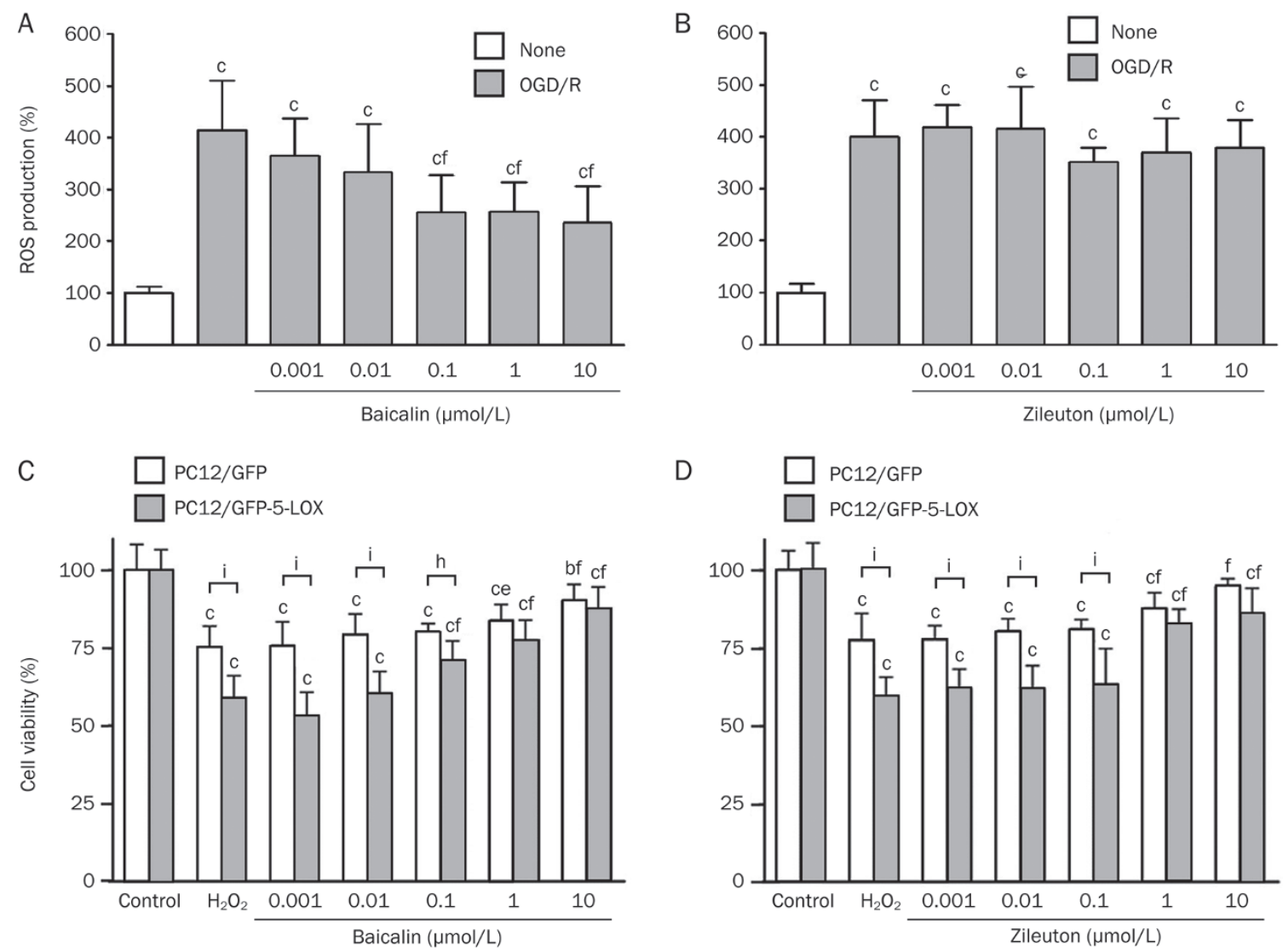

Figure 4. Effects of baicalin and zileuton on OGD/recovery-induced ROS production and $\mathrm{H}_{2} \mathrm{O}_{2}$-reduced viability in PC12 cells. (A and B) ROS production was determined after 2-h OGD and 0.5-h recovery in the absence or presence of baicalin and zileuton in wild-type PC12 cells. Baicalin, but not zileuton, inhibited ROS production. ( $C$ and D) Exposure to $\mathrm{H}_{2} \mathrm{O}_{2}(160 \mathrm{~mol} / \mathrm{L})$ for $24 \mathrm{~h}$ reduced cell viability in GFP-5-LOX-transfected PC12 cells. Over-expression of 5-LOX augmented $\mathrm{H}_{2} \mathrm{O}_{2}$-induced injury in PC12 cells. Baicalin (C) and zileuton (D) attenuated the reduced viability. Data are reported as mean \pm SD. $n=8$. ${ }^{\mathrm{b}} P<0.01,{ }^{\mathrm{c}} P<0.01$ vs control; ${ }^{\mathrm{e}} P<0.05,{ }^{\mathrm{f}} P<0.01$ vs 0 GD alone; ${ }^{\mathrm{h}} P<0.05,{ }^{\mathrm{i}} P<0.01$ vs GFP-transfected cells.

iron at the active site with weak redox-active properties ${ }^{[36,37]}$. Unlike baicalin, it did not possess substantial anti-oxidative activity, as shown in the present and previous studies ${ }^{[14]}$. In addition, zileuton did not inhibit p38 phosphorylation and 5-LOX translocation but did inhibit 5-LOX enzymatic activity and cell injury after exposure to OGD/recovery or $\mathrm{H}_{2} \mathrm{O}_{2}$. These findings indicate that baicalin inhibits 5-LOX activation partly through anti-oxidative activity and inhibition of the ROS/p38 MAPK pathway whereas zileuton directly inhibits 5-LOX activity.

Taking these results together, we conclude that baicalin is not a direct 5-LOX inhibitor but can inhibit oxidative stressinduced 5-LOX activation and the resultant cell injury in PC12 cells via inhibition of the ROS/p38 MAPK pathway in addition to inhibition of NMDA receptor activation, as shown in neurons ${ }^{[13]}$. Furthermore, baicalin exerts various effects ${ }^{[16-19]}$ and can protect against ischemic injury ${ }^{[20-23]}$ and inflamma-

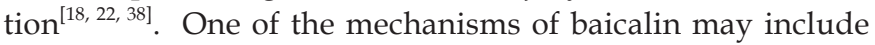
inhibition of 5-LOX activation in these disorders.

\section{Acknowledgements}

This study was supported by the National Natural Science
Foundation of China, № 30672449 and № 30772561. We thank Professor CD FUNK, the Center for Experimental Therapeutics and the Department of Pharmacology at the University of Pennsylvania, USA (now at the Department of Physiology, Queen's University, Canada), for kindly providing the pEGFP/C2-5-LOX and pEGFP/C2 vectors.

\section{Author contribution}

Cheng-tan LI, Wei-ping ZHANG, San-hua FANG, Yun-bi LU, and Er-qing WEI designed the study. Cheng-tan LI, Lihui ZHANG, Ling-ling QI, Xue-qin HUANG, and Xiao-jia HUANG performed the experiments. Cheng-tan LI, Li-hui ZHANG, San-hua FANG, Er-qing WEI wrote the manuscript.

\section{References}

1 Murphy RC, Gijon MA. Biosynthesis and metabolism of leukotrienes. Biochem J 2007; 405: 379-95.

2 Rubin P, Mollison KW. Pharmacotherapy of diseases mediated by 5-lipoxygenase pathway eicosanoids. Prostaglandins Other Lipid Mediat 2007; 83: 188-97.

3 Radmark 0, Samuelsson B. 5-lipoxygenase: regulation and possible involvement in atherosclerosis. Prostaglandins Other Lipid Mediat 2007; 83: 162-74. 
A
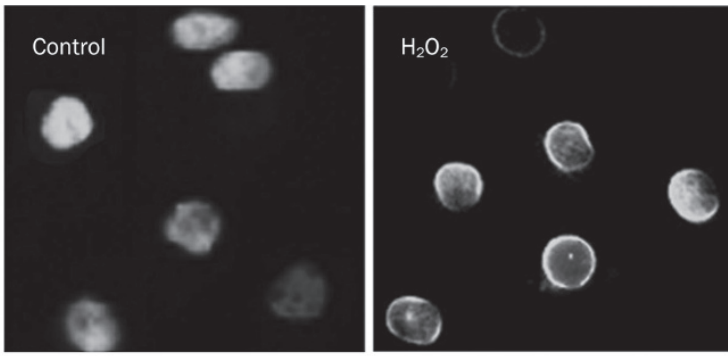

B

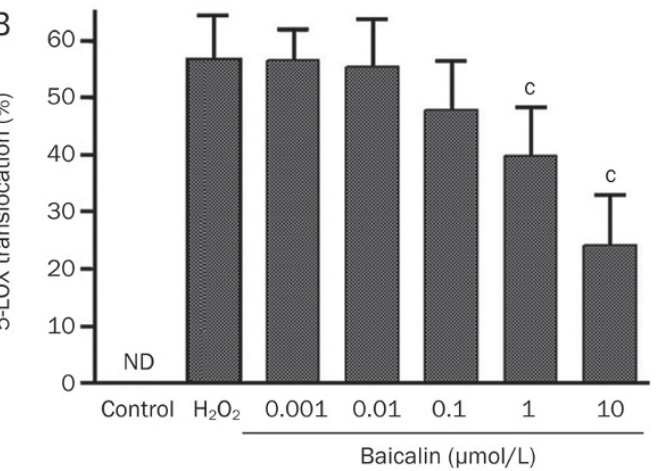

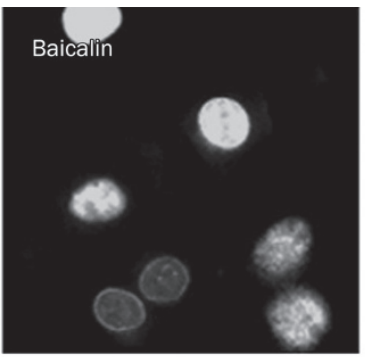

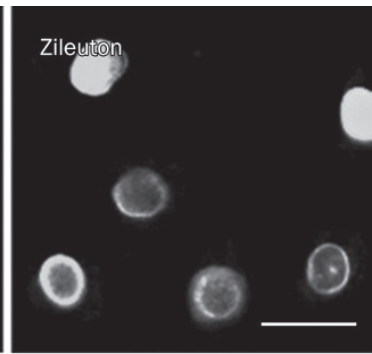

C

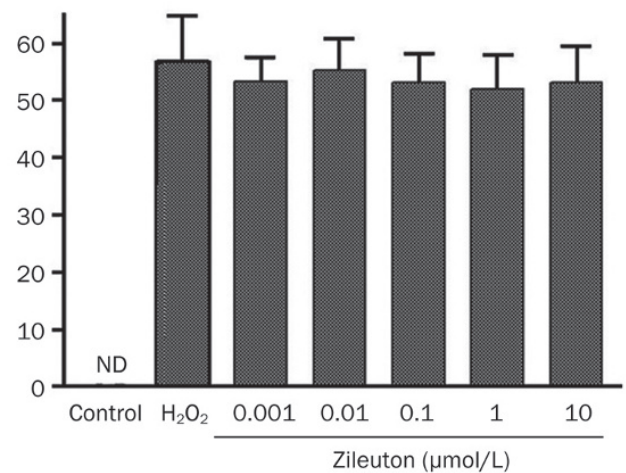

Figure 5. Effects of baicalin and zileuton on $\mathrm{H}_{2} \mathrm{O}_{2}$-induced 5-LOX translocation in GFP-5-LOX-transfected PC12 cells. (A) $\mathrm{H}_{2} \mathrm{O}_{2}(160 \mu$ mol/L)-induced 5-LOX translocation was significantly inhibited by baicalin $(1 \mu \mathrm{mol} / \mathrm{L})$ but not by zileuton $(1 \mu \mathrm{mol} / \mathrm{L})$. Scale bar=20 $\mu \mathrm{m}$. (B and $\mathrm{C}) \mathrm{Concentration}-$ dependent results are reported as mean \pm SD. $n=6-8$. ${ }^{\circ} P<0.01$ vs $\mathrm{H}_{2} \mathrm{O}_{2}$ alone. ND, not detectable.

A
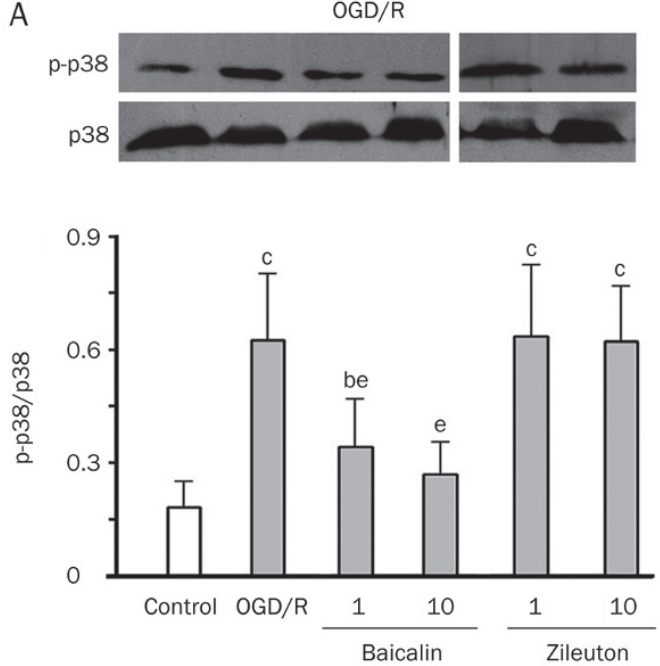

B
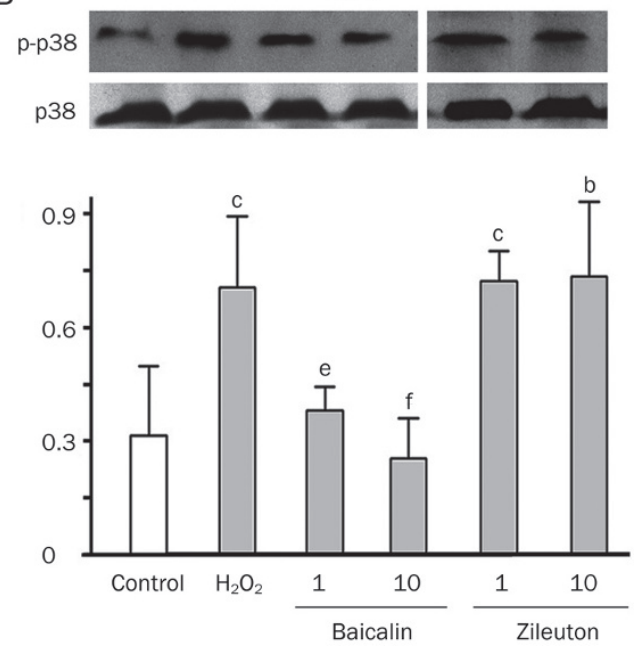

Figure 6. Effects of baicalin and zileuton on OGD/recovery- or $\mathrm{H}_{2} \mathrm{O}_{2}$-induced p38 phosphorylation in GFP-5-LOX transfected PC12 cells. Phosphorylation of p38 was inhibited by baicalin ( 1 and $10 \mu \mathrm{mol} / \mathrm{L}$ ) but not by zileuton after 2 -h OGD/1.5-h recovery (A) and exposure to $\mathrm{H}_{2} \mathrm{O}_{2}(160 \mu \mathrm{mol} / \mathrm{L})$ for $20 \mathrm{~min}$ (B). Data are reported as mean \pm SD. $n=4-6$. ${ }^{b} P<0.05,{ }^{c} P<0.01$ vs corresponding control; ${ }^{e} P<0.05,{ }^{f} P<0.01$ vs 0 GD/recovery or $\mathrm{H}_{2} \mathrm{O}_{2}$ alone. ND, not detectable.

4 Adamjee J, Suh YJ, Park HS, Choi JH, Penrose JF, Lam BK, et al. Expression of 5-lipoxygenase and cyclooxygenase pathway enzymes in nasal polyps of patients with aspirin-intolerant asthma. J Pathol 2006; 209: 392-9.

5 Friedman BS, Bel EH, Buntinx A, Tanaka W, Han YH, Shingo S, et al. Oral leukotriene inhibitor (MK-886) blocks allergen-induced airway responses. Am Rev Respir Dis 1993; 147: 839-44.
6 Ohtsuki T, Matsumoto M, Hayashi Y, Yamamoto K, Kitagawa K, Ogawa $\mathrm{S}$, et al. Reperfusion induces 5-lipoxygenase translocation and leukotriene C4 production in ischemic brain. Am J Physiol 1995; 268 : H1249-57.

7 Ciceri P, Rabuffetti M, Monopoli A, Nicosia S. Production of leukotrienes in a model of focal cerebral ischaemia in the rat. $\mathrm{Br} J$ Pharmacol 2001; 133: 1323-9. 
8 Zhou Y, Fang SH, Ye YL, Chu LS, Zhang WP, Wang ML, et al. Caffeic acid ameliorates early and delayed brain injuries after focal cerebral ischemia in rats. Acta Pharmacol Sin 2006; 27: 1103-10.

9 Chu LS, Fang SH, Zhou Y, Yu GL, Wang ML, Zhang WP, et al. Minocycline inhibits 5-lipoxygenase activation and brain inflammation after focal cerebral ischemia in rats. Acta Pharmacol Sin 2007; 28 : 763-72.

10 Zhou Y, Wei EQ, Fang SH, Chu LS, Wang ML, Zhang WP, et al. Spatiotemporal properties of 5-lipoxygenase expression and activation in the brain after focal cerebral ischemia in rats. Life Sci 2006; 79 : 1645-56.

11 Song Y, Wei EQ, Zhang WP, Zhang L, Liu JR, Chen Z. Minocycline protects PC12 cells from ischemic-like injury and inhibits 5-lipoxygenase activation. Neuroreport 2004; 15: 2181-4.

12 Ge QF, Wei EQ, Zhang WP, Hu X, Huang XJ, Zhang L, et al. Activation of 5-lipoxygenase after oxygen-glucose deprivation is partly mediated via NMDA receptor in rat cortical neurons. J Neurochem 2006; 97 : 992-1004.

13 Ge QF, Hu X, Ma ZQ, Liu JR, Zhang WP, Chen Z, et al. Baicalin attenuates oxygen-glucose deprivation-induced injury via inhibiting NMDA receptor-mediated 5-lipoxygenase activation in rat cortical neurons. Pharmacol Res 2007; 55: 148-57.

14 Li CT, Zhang WP, Lu YB, Fang SH, Yuan YM, Qi LL, et al. Oxygenglucose deprivation activates 5 -lipoxygenase mediated by oxidative stress through the p38 mitogen-activated protein kinase pathway in PC12 cells. J Neurosci Res 2009; 87: 991-1001.

15 Song Y, Wei EQ, Zhang WP, Ge QF, Liu JR, Wang ML, et al. Minocycline protects PC12 cells against NMDA-induced injury via inhibiting 5-lipoxygenase activation. Brain Res 2006; 1085: 57-67.

16 Li-Weber M. New therapeutic aspects of flavones: the anticancer properties of Scutellaria and its main active constituents Wogonin, Baicalein and Baicalin. Cancer Treat Rev 2009; 35: 57-68.

17 Wan JY, Gong X, Zhang L, Li HZ, Zhou YF, Zhou QX. Protective effect of baicalin against lipopolysaccharide/D-galactosamine-induced liver injury in mice by up-regulation of heme oxygenase-1. Eur J Pharmacol 2008; 587: 302-8.

18 Liu LL, Gong LK, Wang H, Xiao Y, Wu XF, Zhang YH, et al. Baicalin inhibits macrophage activation by lipopolysaccharide and protects mice from endotoxin shock. Biochem Pharmacol 2008; 75: 914-22.

19 Chang WT, Shao ZH, Yin JJ, Mehendale S, Wang CZ, Qin Y, et al. Comparative effects of flavonoids on oxidant scavenging and ischemia-reperfusion injury in cardiomyocytes. Eur J Pharmacol 2007; 566: 58-66.

20 Zhang Z, Wu R, Li P, Liu F, Zhang W, Zhang P, et al. Baicalin administration is effective in positive regulation of twenty-four ischemia/ reperfusion-related proteins identified by a proteomic study. Neurochem Int 2009; 54: 488-96.

21 Jung SH, Kang KD, Ji D, Fawcett RJ, Safa R, Kamalden TA, et al. The flavonoid baicalin counteracts ischemic and oxidative insults to retinal cells and lipid peroxidation to brain membranes. Neurochem Int 2008; 53: 325-37.

22 Chang CP, Huang WT, Cheng BC, Hsu CC, Lin MT. The flavonoid baicalin protects against cerebrovascular dysfunction and brain inflammation in experimental heatstroke. Neuropharmacology 2007;
52: 1024-33.

23 Zhang ZJ, Li P, Wang Z, Li PT, Zhang WS, Sun ZH, et al. A comparative study on the individual and combined effects of baicalin and jasminoidin on focal cerebral ischemia-reperfusion injury. Brain Res 2006; 1123: 188-95.

24 Liu LY, Wei EQ, Zhao YM, Chen FX, Wang ML, Zhang WP, et al. Protective effects of baicalin on oxygen/glucose deprivation- and NMDA-induced injuries in rat hippocampal slices. J Pharm Pharmacol 2005; 57: 1019-26.

25 Carter GW, Young PR, Albert DH, Bouska J, Dyer R, Bell RL, et al. 5-lipoxygenase inhibitory activity of zileuton. J Pharmacol Exp Ther 1991; 256: 929-37.

26 Sirois $\mathrm{P}$, Borgeat $\mathrm{P}$, Lauziere M, Dube L, Rubin P, Kesterson J. Effect of Zileuton (A-64077) on the 5-lipoxygenase activity of human whole blood ex vivo. Agents Actions 1991; 34: 117-20.

27 Chen XS, Zhang YY, Funk CD. Determinants of 5-lipoxygenase nuclear localization using green fluorescent protein/5-lipoxygenase fusion proteins. J Biol Chem 1998; 273: 31237-44.

28 Burnett BP, Jia Q, Zhao Y, Levy RM. A medicinal extract of Scutellaria baicalensis and Acacia catechu acts as a dual inhibitor of cyclooxygenase and 5-lipoxygenase to reduce inflammation. J Med Food 2007; 10: 442-51.

29 Guan ZZ. Cross-talk between oxidative stress and modifications of cholinergic and glutaminergic receptors in the pathogenesis of Alzheimer's disease. Acta Pharmacol Sin 2008; 29: 773-80.

30 Hernandez-Fonseca K, Cardenas-Rodriguez N, Pedraza-Chaverri J, Massieu L. Calcium-dependent production of reactive oxygen species is involved in neuronal damage induced during glycolysis inhibition in cultured hippocampal neurons. J Neurosci Res 2008; 86: 1768-80.

31 Pearson G, Robinson F, Beers Gibson T, Xu BE, Karandikar M, Berman $\mathrm{K}$, et al. Mitogen-activated protein (MAP) kinase pathways: regulation and physiological functions. Endocr Rev 2001; 22: 153-83.

32 Kumar S, Boehm J, Lee JC. p38 MAP kinases: key signalling molecules as therapeutic targets for inflammatory diseases. Nat Rev Drug Discov 2003; 2: 717-26.

33 Cuenda A, Rousseau S. p38 MAP-kinases pathway regulation, function and role in human diseases. Biochim Biophys Acta 2007; 1773: 1358-75.

34 Werz 0, Klemm J, Radmark 0, Samuelsson B. p38 MAP kinase mediates stress-induced leukotriene synthesis in a human B-lymphocyte cell line. J Leukoc Biol 2001; 70: 830-8.

35 Werz O, Burkert E, Samuelsson B, Radmark O, Steinhilber D. Activation of 5-lipoxygenase by cell stress is calcium independent in human polymorphonuclear leukocytes. Blood 2002; 99: 1044-52.

36 Werz 0, Steinhilber D. Development of 5-lipoxygenase inhibitors-lessons from cellular enzyme regulation. Biochem Pharmacol 2005; 70: 327-33.

37 Werz 0, Steinhilber D. Therapeutic options for 5-lipoxygenase inhibitors. Pharmacol Ther 2006; 112: 701-18.

38 Tian H, Zhang X, Wu C, Chen L, Ying R, Ye J, et al. Effects of baicalin and octreotide on the serum TNF-alpha level and apoptosis in multiple organs of rats with severe acute pancreatitis. Inflammation 2009; 32: 191-201. 